Runnig head: SELF-CONTROL DEMANDS AND PSYCHOLOGICAL DETACHMENT 1

1

2

3

4

5

6 This is an accepted manuscript version for an article to be published in the European Journal

7 of Work and Organizational Psychology. Copyright to the final published article belongs to

8 Taylor \& Francis Group. The published version of the article may be different from the

9 present one.

10

11 If you wish to cite this paper, please use the following reference:

12

13 Rivkin, W., Diestel, S., \& Schmidt, K.-H. (2015). Psychological detachment: A moderator in

14 the relationship of self-control demands and job strain. European Journal of Work and

15

Organizational Psychology, 24(3), 376-388. https://doi.org/10.1080/1359432X.2014.924926 
29 Psychological Detachment: A Moderator in the Relationship of Self-Control Demands and 
Abstract

32 In the present article, we investigate psychological detachment as a moderator of the positive relationship of self-control demands (SCDs) and indicators of psychological strain. Based on

34 the propositions that a) SCDs are a source of work stress, which draws on and depletes

35 limited regulatory resources, and b) psychological detachment facilitates the recovery of that resource, we expected that psychological detachment attenuates the positive relationships between SCDs and psychological strain (ego depletion, need for recovery, emotional exhaustion and depersonalization). We tested our prediction in two different studies with hierarchical moderated regression analyses. Results of the first study $(\mathrm{N}=445)$ provided strong support for our prediction that psychological detachment buffers the adverse impact of SCDs on strain. In the second study $(\mathrm{N}=426)$, we replicated our initial findings and tested the theoretical assertion that psychological detachment is more effective in buffering those stressors that deplete limited regulatory resources (SCDs) in contrast to stressors (job ambiguity), which are considered to cause strain through other mechanisms. Contrastive comparisons of the differential interaction patterns of psychological detachment with stressors that induce self-control efforts and job ambiguity, supported our prediction that psychological detachment is more effective in attenuating the adverse effects of SCDs on psychological strain.

Keywords: Self-control demands, psychological detachment, burnout, recovery. 


\section{Psychological Detachment: A Moderator in the Relationship of Self-Control Demands and Job Strain}

The rise of the service-sector in industrialized countries has led self-control demands (SCDs) to become an integral part of the employee work role (Cascio, 2003; Pulakos, Arad, Donovan, \& Plamondon, 2000). Self-control involves inhibiting, modifying, or overriding spontaneous and automatic reactions, urges, emotions, and desires that would otherwise interfere with goal-directed behavior and impede goal achievement at work (Baumeister, Heatherton, \& Tice, 1994). According to the Model of Self-Control Strength (Muraven \& Baumeister, 2000), different processes of self-control draw on and consume a common limited regulatory resource capacity. In line with this well-founded proposition, research revealed that SCDs at work that require individuals to engage in self-control result in strain and impaired well-being (Diestel \& Schmidt, 2011). Hence, to protect employees from the adverse consequences of SCDs, studies have focused on moderators such as self-control capacity (Schmidt, Hupke, \& Diestel, 2012), organizational commitment (Schmidt \& Diestel, 2012), and job control (Neubach \& Schmidt, 2006), which attenuate the positive relationships of SCDs and indicators of psychological strain.

However, research on moderators of the relationship between SCDs and job strain suffers from several drawbacks. First, even though empirical evidence suggests that SCDs predict strain (e.g. Diestel \& Schmidt, 2011), only few moderators that buffer this relationship have been examined so far. Second, previous research has mostly focused on moderators that are stable and can hardly be influenced by employees (e.g. job control; Neubach \& Schmidt, 2006). Thus, research should provide evidence on protective moderators that are more malleable and open to change and development for employees. We address these drawbacks by examining psychological detachment (also referred to as detachment) as a moderator of the relationship between SCDs and strain. Psychological detachment is 
defined as an "(...) individual's sense of being away from the work situation" (Etzion, Eden, \& Lapidot, 1998, p. 579). Conceptualized as an experienced state in which employees mentally disengage from work during non-work time (Sonnentag \& Bayer, 2005), we expect detachment to facilitate recovery of the limited regulatory resource that is depleted through SCDs and thus, to attenuate the adverse impact of work-related SCDs on strain.

With the present research, we aim to enhance current literature on self-control in at least two ways: First, we examine psychological detachment as a moderator that is expected to buffer the adverse impact of SCDs on strain. Because from an individual's perspective psychological detachment is considered to be more malleable than moderators that have been examined so far, our research might offer employees better opportunities to reduce the adverse consequences of SCDs at work. Second, we integrate theories from the field of selfcontrol and recovery research to shed light on the mechanisms that underlie the beneficial effects of psychological detachment. We integrate the Model of Self-Control Strength (Muraven \& Baumeister, 2000) and the Effort-Recovery Model (Meijman \& Mulder, 1998), which propose that a reduction of effort reverses physical and psychological load reactions and facilitates recovery, and we propose that psychological detachment should restore the limited regulatory resource, which is depleted by work-related SCDs.

In two studies we test moderating effects of psychological detachment on the relationship between SCDs and indicators of strain (ego depletion, need for recovery, emotional exhaustion and depersonalization). In line with our argument that psychological detachment restores regulatory resources, it may not be an effective buffer against the adverse impacts of other types of work-related stressors. Thus, we propose that psychological detachment is more effective in buffering the adverse impacts of those stressors that deplete limited regulatory resources (e.g. SCDs) as opposed to stressors which exert their adverse effects through other mechanisms. Consequently, in a second study, we examine the 
100

101

102

103

104

105

106

107

108

109

110

111

112

113

114

115

116

117

118

119

120

121

122

123

moderating effect of psychological detachment on the positive relationship between job ambiguity and strain. Job ambiguity indicates employees' lack of job-related information (Breaugh \& Colihan, 1994). Previous research has demonstrated that job ambiguity exerts its adverse effects on strain predominantly through negative appraisal mechanisms (Monat, Averill, James, \& Lazarus, 1972). We expect detachment to be less effective in buffering the adverse impact of job ambiguity on strain than the adverse impact of SCDs because it induces enduring stressful states due to negative appraisal even in non-work time that should not be counteracted by detachment.

In the following, we first review the literature on self-control. Then, the concept of detachment will be briefly discussed. Afterwards, we integrate both lines of research to elaborate on the mechanism that underlies the buffering effect of psychological detachment.

\section{Self-control demands: A source of stress at work}

Results from research on self-control indicate that exerting self-control can lead to impairments in cognitive and behavioral control (Muraven, Tice, \& Baumeister, 1998;

Schmeichel, Vohs, \& Baumeister, 2003). In a series of experimental studies that demanded two successive acts of self-control (e.g. suppressing emotions, attention control), self-control performance on the second act was consistently impaired even in a seemingly unrelated sphere of activity (Hagger, Wood, Stiff, \& Chatzisarantis, 2010). Muraven and Baumeister (2000) developed the Model of Self-Control Strength to account for these findings. They labeled the state of short-term reduction in the capacity to engage in self-control as ego depletion (Baumeister, Bratslavsky, Muraven, \& Tice, 1998). The model further predicts that the inability to recover the regulatory resource due to recurrent requirements to exert selfcontrol may lead to chronic deficits that can manifest in high levels of strain and impaired well-being (Muraven \& Baumeister, 2000). 
Recent research on occupational stress and health has also demonstrated that the demands on self-control constitute a major stressor at work. Schmidt and Neubach (2007) examined different forms of SCDs at work and their cumulative effects on job strain. SCDs are conceptualized to cause employees to engage in self-control and thus, to deplete limited regulatory resources. In particular, SCDs involve a set of the following work-related requirements: To control or inhibit spontaneous responses and associated affective states which manifest for example in injudicious expressions (impulse control); to ignore or resist distractions evoked by task irrelevant stimuli (resisting distractions); and to overcome motivational deficits that result from unattractive tasks (overcoming inner resistances). On the basis of several samples from different occupational contexts, cross-sectional and longitudinal studies revealed that SCDs predict indicators of job strain and impaired wellbeing (e.g. burnout, depressive symptoms, and absenteeism; Diestel \& Schmidt, 2011, 2012). In line with the Model of Self-Control Strength the psychological costs of SCDs are considered to result from repeated depletion of limited regulatory resources (see also Oaten \& Cheng, 2005). Consequently, the model predicts that in cases of high SCDs and associated states of ego depletion, recovery of the regulatory resource can be expected to prevent strain. However, we know of no study that has focused on recovery experiences that may restore regulatory resources and thus buffer the adverse effects of SCDs. Drawing on recovery research (Sonnentag \& Fritz, 2007), psychological detachment (a state,which enables employees to mentally disengage from work) may be able to restore limited regulatory resources that are taxed by SCDs at work. Thus, in the present study, we examine whether detachment attenuates the positive relationship between SCDs and strain.

\section{Psychological detachment}

First evidence for the benefits of psychological detachment were provided by Etzion et al. (1998) who found that participants who signed up for reserve military service and 
149 thereby experienced detachment from their jobs reported lower levels of stress and strain

150 when returning to their previous jobs than individuals who did not sign up for reserve

151 military service and thus, did not experience psychological detachment. Consequently,

152 detachment implies that short-term mental absence from work (e.g. in leisure time) may have

153 beneficial effects on strain. Similarly, Sonnentag and Bayer (2005) found that employees who

154 experienced higher levels of detachment from work during leisure time reported an increased positive mood and decreased feelings of fatigue at bedtime.

Sonnentag and Fritz (2007) argue that during periods of psychological detachment, employees experience a reduction of job demands and a break from work-related stressors.

Thereby, detachment facilitates recovery processes, which enhance psychological well-being

159 (Meijman \& Mulder, 1998). In contrast, individuals who are unable to detach from work in leisure time return to work in a less recovered state. In such a state, handling stressors becomes even more effortful and thus, results in increased strain (Binnewies, Sonnentag, \& Mojza, 2009).

Further research on recovery experiences supported the notion that psychological detachment reduces psychological strain, over time (e.g. emotional exhaustion, need for recovery, and psychosomatic complaints; Sonnentag, Binnewies, \& Mojza, 2010; Sonnentag, detachment moderates (buffers) the adverse effects of job stressors (e.g. job demands) on strain and well-being.

\section{Buffering effects of psychological detachment}

Going beyond previous research and connecting the domains of SCDs and recovery research, we argue that psychological detachment may contribute to the recovery of the

172 regulatory resource, which is depleted by high job-related SCDs. Thus, in cases of high

173 SCDs, detachment is expected to prevent SCDs to manifest in indicators of strain. Based on 
the assumptions that a) SCDs are a source of work stress, which draws on and depletes a limited regulatory resource, and b) detachment contributes to the recovery of that resource, we expect SCDs to interact with detachment in predicting strain. More specifically, the positive relationships between SCDs and indicators of psychological strain are hypothesized to be attenuated (buffered) as function of psychological detachment.

Our predictions derive from the Effort-Recovery Model (Meijman \& Mulder, 1998) and the Model of Self-Control Strength (Muraven \& Baumeister, 2000). The Effort-Recovery Model suggests that effort at work leads to physical and psychological load reactions (e.g. fatigue, physical arousal). These load reactions can be reversed through reduction of workrelated effort. On the contrary, if individuals are exposed to prolonged work-related effort, load reactions become irreversible and manifest in strain and impaired psychological wellbeing. On the basis of this theoretical notion, Sonnentag et al. (2010) argue that through the absence of work-related thoughts psychological detachment in leisure time reduces workrelated effort. Thus, we propose that during periods of detachment in leisure time workrelated SCDs cease to deplete limited regulatory resources. Thus, psychological detachment interrupts load reactions (depletion) on the limited regulatory resource resulting from workrelated SCDs. Thereupon, load reactions are reversed and the limited regulatory resource can be restored. Put differently, our proposition implies that individuals experiencing high levels of detachment in leisure time are less strained by high SCDs at work than individuals that experience low levels of detachment. We argue that this effect results from the recovery of the regulatory resource due to detachment. Hence, we propose the following hypothesis: Hypothesis 1: Psychological detachment moderates the positive relationship of SCDs to indicators of job strain in such a way that the relationship is attenuated as a function of psychological detachment. 
We test the effects of psychological detachment on different indicators of job strain and well-being. We use ego depletion and need for recovery as short-term indicators of psychological well-being. Ego depletion refers to a state of regulatory resource depletion and an inner experience of exhaustion resulting from SCDs (Baumeister et al., 1998). Need for recovery reflects the need to recuperate from work tasks that is strongest in the last hours of work and directly after work (Van Veldhoven \& Broersen, 2003). Additionally, we use the burnout dimensions emotional exhaustion and depersonalization to demonstrate that psychological detachment also attenuates the effects of SCDs on long-term indicators of strain. Emotional exhaustion is considered as the main component of burnout and is defined as a state of depletion and fatigue resulting from one's work (Maslach \& Jackson, 1981). Depersonalization, another dimension of burnout, refers to the development of negative and cynical feelings towards people at work (Maslach \& Jackson, 1981).

\section{Study 1}

\section{Methods}

\section{Participants}

The data for our first study was obtained in cooperation with a German health care provider. Data from 445 healthy participants was collected during a voluntary medical checkup. The aim of this check-up was to assess employees' physical and psychological health and identify risk factors that may impair employees' health. Data collection was conducted by physicians that applied self-report measures of all study variables. Most participants were occupied in the financial sector and provided customer service and sold financial products. Thus, they interacted with clients on a regular basis. Because most people tend to be very cautious about issues concerning money, employees were expected to explain products and services multiple times to ensure that customers understand all details. Additionally, to encourage customers to entrust their money to the financial institution, employees must 
223

224

225

226

227

228

229

230

231

232

233

234

235

236

237

238

239

240

241

242

243

244

control impulses to refrain from speaking and behaving in a way that creates an atmosphere of distrust and insecurity. Employees also frequently deal with difficult customers, foremost when handling complaints (e.g. false transactions or illegitimate withdrawals). During these interactions, employees always have to remain friendly even when responding to clients that behave in a rude or unfriendly manner. These job descriptions imply that self-control is an integral part of the participants' work roles. Because participants signed up voluntarily for examination, the response rate was $100 \%$. The proportion of female participants was $29.0 \%$ and age ranged from 35 to 63 years $(\mathrm{M}=49.77 ; \mathrm{SD}=6.00)$.

\section{Measures and control variables}

We assessed SCDs with ten items from the SCDs scale developed by Schmidt and Neubach (2007). On a 5-point Likert scale $(1=$ not at all; $5=$ a great deal), participants rated their work in terms of the requirements to resist distractions, overcome inner blockades, and control impulses to maintain behaviours at work that are controlled and restrained.

Exemplary items are "My job requires me never to lose my temper" and "I am never allowed to lose my self-control at work". Because all three facets of SCDs were expected to draw on and deplete a common regulatory resource, we computed the scale score as the average of the single item scores (see also Schmidt et al., 2012).

Psychological detachment (four items) was assessed with the detachment subscale from the recovery experience questionnaire developed by Sonnentag and Fritz (2007).

Participants were asked to indicate the extent to which they are occupied with job-related thoughts in leisure time $(1=$ not at all; $5=$ a great deal $)$. A typical item from the scale is “During evenings, I don't think about work at all".

To assess ego depletion, we used four items from the German translation (Bertrams, Unger, \& Dickhäuser, 2011) of the state self-control capacity scale from Ciarocco, Twenge, Muraven, and Tice (2007). An example for an item is "I feel like my willpower is gone". 
248 Need for recovery was measured with five items from the Need for Recovery Scale (Van

249 Veldhoven \& Broersen, 2003). An item from the scale is "I find it difficult to relax at the end

250 of a working day." Ego depletion and need for recovery were both rated on a 4-point Likert

251 scale $(1=$ never; 5 = always $)$.

252

The burnout dimensions of emotional exhaustion (eight items) and depersonalization

253 (four items) were assessed with the German translation (Büssing \& Perrar, 1992) of the

254 Maslach Burnout Inventory (Maslach \& Jackson, 1981; 1986). Exemplary items are "I feel

255 emotionally drained from my work" (emotional exhaustion) and "I have become more callous

256 toward people since I took this job" (depersonalization). The items were rated on a 6-point

257 Likert scale $(1=$ not at all; $5=$ very strong $)$

258 Results

259

260

261

262

263

264

265

266

267

268

269

270

271

Descriptive statistics including internal consistencies are presented in Table 1.

- Insert Table 1 about here -

\section{Measurement models}

We conducted confirmatory factor analyses (CFA) to test the differentiability of the predictors and the criterion variables. SCDs and psychological detachment were tested in a one-factor model that integrates both predictors into one factor, and a two-factor model that specifies SCDs and detachment as separate constructs. Fit indices indicated that a two-factor model yielded a better data approximation for the predictors than a one-factor model (cf. Table 2).

CFAs also provided support for the psychometrical distinctiveness of all outcome variables. We tested ego depletion, need for recovery, emotional exhaustion and depersonalization in a four-factor model that yielded a good data approximation (cf. Table 2). In contrast, a one-factor model showed a poor fit (cf. Table 2). In sum, measurement models 
272 that distinguished between the predictor and the criterion variables accordingly, provided the 273 best data fit.

274

275

276

277

278

279

280

281

282

283

284

285

286

287

288

289

290

291

292

293

294

295

296

- Insert Table 2 about here -

\section{Analysis of main and interaction Effects}

We tested our hypothesis that psychological detachment moderates the relationship

between SCDs and indicators of strain by means of hierarchical moderated regression. In the first step, we entered demographic variables (age and gender) into the regressions to control for their potential confounding influences on the relationships under examination. In the second step, we added the main predictors SCDs and detachment. In the third step, the interaction term between SCDs and detachment was added into the regressions. The significance test for the interaction effect is based on the variance explained by the crossproduct over and above that accounted for by the main effects. To avoid biased estimations due to multicollinearity, we standardized both predictors prior to calculating the crossproduct term (cf. Aiken \& West, 1991).

The results are presented in Table 3. After controlling for biographical data, SCDs and detachment yielded significant effects on all indicators of strain, with signs corresponding to expectations. The direct effects were positive for SCDs and negative for detachment (cf. Table 3). Moreover, and theoretically more important, the interaction effects of SCDs and detachment explained additional and significant proportions of variance in all outcomes (cf. Table 3). The incremental amounts of variance explained by the interaction effects varied between $1 \%$ and $2 \%$.

- Insert Table 3 about here -

To facilitate the interpretation of the findings, we plotted the interaction patterns (cf. Figure 1). As can be seen, SCDs and detachment had a comparable interactive influence on all indicators of strain, the form of which clearly confirms the hypothesized buffer function of 
psychological detachment. For employees with low levels of detachment, the adverse impact of SCDs on all four indicators of strain were much more pronounced than for employees with high levels of detachment. Thus, we were able to confirm our hypothesis in the first sample. Simple slope analyses (Aiken \& West, 1991) demonstrated that for all outcomes the slopes for high (one SD above the mean) and low (one SD below the mean) detachment were significantly different from zero (cf. Figure 1). Thus, detachment does not completely nullify the adverse effect of SCDs but rather mitigates the adverse effects of SCDs on strain.

- Insert Figure 1 about here -

\section{Discussion of Study 1}

The findings of our initial study provide support for our prediction that detachment attenuates the adverse effect of SCDs on strain. Our analyses demonstrate that the positive relationships between SCDs and indicators of psychological strain (ego depletion, need for recovery, emotional exhaustion and depersonalization) were attenuated as a function of detachment. Thus, employees who detach from work in leisure time are less susceptible to strain resulting from high SCDs, compared to employees who do not detach from work in leisure time.

Even though, our first study provides convincing evidence for the buffering effect of psychological detachment, some aspects still remain unclear. First, it is not certain whether and to what extent the buffering effect of detachment is generalizable across different samples and contexts. Second, in light of our proposition that the buffering function of detachment is essentially based upon the psychological mechanism of recovery of limited regulatory resources (required for coping with SCDs), it is also unclear, whether detachment may also attenuate the adverse effects of stressors, which operate and tax other mechanisms than depletion of regulatory resources. To address these points, we conducted a second study which aimed at testing the moderating effect of detachment on the adverse impact of SCDs in 
another sample. In addition, we examined the effects of detachment on the positive relationship of job ambiguity and strain. Evidence on differential moderating effects of detachment on different stressor-strain relationships may point to relevant work-related boundary conditions under which detachment may or may not be useful to prevent strain.

\section{Study 2}

\section{Differential interaction effects of psychological detachment with SCDs and job} ambiguity

In Study 1, we demonstrated that psychological detachment buffers the adverse impact of SCDs on strain. In Study 2, we seek to test whether detachment can also buffer other stressor-strain relationships. Thus, we examine detachment as a moderator of the adverse impact of job ambiguity on strain. Role theory suggests that job ambiguity is considered to be an inherently "noxious" (Kahn, Wolfe, Quinn, Snoek, \& Rosenthal, 1964), and thus, stressful state (Breaugh \& Colihan, 1994). In general, job ambiguity is characterized by high uncertainty, a lack of opportunities to plan ahead and unpredictable events that cause employees to engage in coping strategies such as defensive strategies which distort the reality of the situation. These coping strategies should increase the probability that individuals will be dissatisfied with their job role (Rizzo, House, \& Lirtzman, 1970) and lead to strain through detrimental individual appraisal processes (Monat et al., 1972). On the basis of our theoretical proposition that the adverse effect of job ambiguity is mainly driven by other mechanisms than regulatory resource depletion (e.g. appraisal processes; Monat, et al., 1972), we predict that restoring the regulatory resources through detachment should be less effective in buffering the adverse impact of job ambiguity on strain than the adverse impact of SCDs. Hence, we propose the following hypothesis:

Hypothesis 2: The buffering effect of psychological detachment is stronger on the relationship of SCDs with strain than on the relationship of job ambiguity with strain. 


\section{Method}

\section{Participants}

The participants of the second study were recruited from a German financial service provider. 705 employees were contacted via e-mail to participate in an online survey that was conducted during normal working hours. Out of all contacted employees, 458 employees agreed to participate in our survey. Because of missing responses, 32 individuals were excluded from the analyses. Hence, the overall response rate was $60.4 \%$. The final analyses were conducted on the basis of a sample of $\mathrm{N}=426$ persons. Because we addressed employees from different departments of the organization, we received data from individuals working in different occupational fields. A major part of our sample (73\%) worked as financial consultants. Like the participants in the first sample, their main task was selling products and consulting customers (e.g. private customers, business customers). Another part of the sample (15\%) worked in the administration department, and $12 \%$ were employed in managerial positions and thus, had leadership responsibilities. The work of last both groups was characterized by less frequent client interactions than the work of consultants.

Additionally, at work these employees have to face situations that are characterized by lack of information about work methods, work-schedules and goals. For example, financial consultants have to decide about customers being credit-worthy based on the incomplete information that they receive from clients. Furthermore, because clients may arrive and call anytime requesting customer service, it is difficult for employees to properly structure their work tasks. These examples indicate that in their jobs, participants experience different facets of job ambiguity. Again, participation was voluntary and all participants were assured that their responses would remain confidential. Participants' age ranged from 18 to 60 years $(\mathrm{M}=$ $39.12 ; \mathrm{SD}=10.64)$. Out of all participants, $44 \%$ were women, and $23 \%$ were part-time employed. The mean organizational tenure was 18.1 years $(\mathrm{SD}=10.85)$. 


\section{Measures and control variables}

The assessment of SCDs, psychological detachment, ego depletion, need for recovery, emotional exhaustion, and depersonalization were based on the same instruments as in the first study.

Job ambiguity was measured with nine items from a scale developed by Breaugh and Colihan (1994), which was translated and validated in German language by Sodenkamp and Schmidt (2000). On a 7-point Likert scale $(1=$ not at all; $7=$ a great deal $)$, participants indicated their perceived lack of job-related information with regard to work methods, workschedules and goals. Because these three facets of job ambiguity are closely related, we integrated them into a single scale score as recommended by Breaugh and Colihan (1994). An example for an item is "I know how to get my work done (what procedures to use)". All items were recoded so that higher scores indicated higher job ambiguity.

\section{Results}

\section{Descriptive statistics}

Descriptive statistics including internal consistencies are presented in Table 4. - Insert Table 4 about here -

\section{Measurement models}

Confirmatory factor analyses were used to test the differentiability of the predictors. In the second sample, SCDs, job ambiguity, and psychological detachment were tested as separate factors in a three-factor model (cf. Table 5). Fit indices demonstrated that a threefactor model yielded a better data approximation for the predictors than a one-factor model that integrates all predictors into one construct (cf. Table 5). CFAs also provided support for the distinctiveness of all outcome variables. As in the first study, ego depletion, need for recovery, emotional exhaustion, and depersonalization were tested in a four-factor model 
396

397

398

399

400

401

402

403

404

405

406

407

408

409

410

411

412

413

414

415

416

417 initial support for Hypothesis 2, that the interaction effect of detachment and SCDs on strain 418 419

which indicated a good data approximation (cf. Table 5). By way of comparison, a one-factor model provided a worse fit (cf. Table 5).

- Insert Table 5 about here -

\section{Analysis of main and interaction effects}

As in the first study, we conducted hierarchical moderated regression analyses to test our hypotheses. In the first step, we added control variables (gender, age, leadership position and working time status) into the regressions predicting indicators of strain. In the second step, we introduced the main predictors SCDs, job ambiguity, and detachment into the regressions. In the third step, the interaction terms between SCDs and detachment on the one hand and job ambiguity and detachment on the other hand were entered into the regressions. Again, before calculating the product terms and introducing all variables into the regressions, predictors were standardized, in order to reduce the risk of multicollinearity (cf. Aiken \& West, 1991).

The moderated regression results are presented in Table 6. As in the first study, SCDs and detachment yielded significant direct effects on all indicators of strain with signs corresponding to expectations (cf. Table 6). In addition, job ambiguity was negatively related to all indicators of strain (cf. Table 6).

In accordance with Hypothesis 1, the interaction term between SCDs and psychological detachment accounted for significant amounts of variance in all indicators of strain (cf. Table 6). In contrast, the interaction term of job ambiguity and detachment did not explain additional proportions of variance in all outcomes (cf. Table 6). These results provide is stronger than the interaction effect of detachment and job ambiguity on strain.

- Insert Table 6 about here - 
To compare the strength of the SCDs-detachment and the job ambiguity-detachment

421 interactions on strain, we computed the differences ( $\left.\beta_{\text {diff }}\right)$ between both interaction terms

422 (SCDs-detachment and job ambiguity-detachment) for all indicators of strain and calculated $42390 \%$ confidence intervals (CI; Zou, 2007). A CI that did not include zero indicates a

424

significant difference between both interaction terms at the 5\% level (one-tailed test). For ego depletion and need for recovery, the differences between interaction terms were $\beta_{\text {diff }}=-0.65$ and $\beta_{\text {diff }}=-0.08$, respectively. The $90 \%$ CIs for both short-term outcomes (ego depletion: $.177, .048$; need for recovery: $-.187, .038$ ) did include zero indicating that detachment was not stronger in buffering the adverse effects of SCDs than the adverse effects of job ambiguity on these indicators of strain. For emotional exhaustion and depersonalization, the differences between both interaction terms were $\beta_{\text {diff }}=-0.14$ and $\beta_{\text {diff }}=-0.13$, respectively. For these outcomes, both 90\% CIs (emotional exhaustion: -.252, -.027; depersonalization: $.242,-.017)$ did not include zero indicating that the SCDs-detachment interaction was significantly stronger than the job ambiguity-detachment interaction. In sum, our results show that detachment is more effective in buffering the adverse effects of SCDs than the adverse effects of job ambiguity on emotional exhaustion and depersonalization.

We plotted the significant interaction effects of SCDs and psychological detachment and conducted simple slope analyses (Aiken \& West, 1991) which demonstrated that the form of the moderating effects of detachment is comparable to those reported in the first study (cf. Figure 2).

- Insert Figure 2 about here -

\section{General discussion}

The aims of the present studies were first to provide evidence that detachment attenuates the relationship between SCDs and strain across different samples and second to test the consistency of the buffering function of detachment across different kinds of 
445 stressors. We conducted two studies to analyse the hypothesized relationships and

446 demonstrated that detachment indeed buffers the positive relationships between SCDs and

447 indicators of strain (ego depletion, need for recovery, emotional exhaustion, and

448 depersonalization). In Study 2, we further analysed whether the moderating effect of

449 detachment is a) generalizable across different samples and b) is also valid for stressors that

450 rely foremost on other mechanisms than regulatory resource depletion to cause strain. Again,

451 the results of our second study indicate that detachment buffers the relationship between

452 SCDs and indicators of strain demonstrating that our findings are generalizable across

453 different samples. Furthermore, we tested moderating effects of detachment on the adverse

454 impact of job ambiguity on strain and conducted contrastive comparisons between the SCDs-

455 detachment and job ambiguity-detachment interactions. Difference tests of the interaction

456 terms demonstrated a stronger effect of the SCDs-detachment interaction than the job

457 ambiguity-detachment interaction on the outcomes of emotional exhaustion and

458 depersonalization.

All in all, the present research contributes to the current stress literature in at least four ways. First, our results deliver empirical evidence for detachment as a further moderator of

461 the relationship between SCDs and strain. Second, it provides evidence for the adverse

462 effects of SCDs and the buffering effects of detachment in multiple samples and for multiple

463 indicators of strain. Third, the present research integrates theories from the field of self-

464 control and recovery research to disentangle the mechanism that is responsible for the

465 attenuating effect of detachment. This mechanism involves recovery of the regulatory

466 resource that is depleted through SCDs at work. Fourth, our results demonstrate that

467 detachment is more effective in buffering SCDs that are supposed to deplete limited

468 regulatory resources as compared to job ambiguity that is supposed to cause strain through

469 other mechanisms such as adverse appraisal processes. Differential effects of detachment on 
470 different stressor-strain relationships indicate that psychological detachment did not buffer

471 the adverse effects of all stressors but that it is only effective in buffering the adverse effects

472 of stressors that deplete limited regulatory resources.

\section{Theoretical and practical implications}

474

475

476

477

478

479

480

481

482

483

484

485

486

487

488

489

490

491

492

493

494

From a theoretical perspective, we integrate the lines of research on self-control and recovery: The proposed recovery mechanism adds to our understanding of the relationships between stressors, indicators of strain and psychological resources. It is possible that previously published attenuating effects of detachment on specific stressor-strain relationships such as job demands (Sonnentag et al., 2010) or workplace conflicts (Sonnentag \& Nägel, 2013) may at least partially rely also on recovery of regulatory resources. For example, during workplace conflicts employees need to inhibit spontaneous responses such as outbursts of anger. Since inhibiting spontaneous responses is also an integral part of the SCDs construct (Schmidt \& Neubach, 2007) and thus is thought to deplete regulatory resources, one might argue that the moderating effects of detachment on the adverse effects of workplace conflicts may be based upon recovery of regulatory resources.

From a practical point of view, findings in the present sour findings suggest that detachment is able to reduce the adverse consequences of stressors that deplete regulatory resources, such as SCDs. Thus, to prevent adverse consequences of these stressors, practitioners need to develop interventions at the organizational and at the individual level that enable detachment from work in leisure time. From the organizational point of view, reducing day specific work hours, workload and time pressure may facilitate detachment. Sonnentag and Bayer (2005) argue that these factors contribute to a prolonged activation of job-related thoughts, which drag on into employees' leisure time. Thus, reducing these factors should improve detachment. Another aspect of modern work that hinders employees to detach from work is the increasing use of work-related mobile communication devices, 
495 (Lanaj, Johnson, \& Barnes, 2014). Work-related communication in leisure time may remind

496 employees of work related issues and thus prevent detachment. Therefore, it may be useful

497 for organizations to establish policies or guidelines for the use of mobile communication

498 devices. For example, car manufacturer Volkswagen disables e-mail communication 30

499 minutes after the end of the working day and allows it 30 minutes before the start of the next

500 working day (Spiegel Online, 2011).

$501 \quad$ From the individual perspective, employees may also enhance psychological

502 detachment by refraining from using work-related communication technologies in leisure

503 time. Furthermore, Ashforth, Kreiner, and Fugate (2000) proposed that high segmentation

504 between work and private life may prevent employees from being occupied with work-related

505 issues during leisure time and thus, enhance psychological detachment. In line with this

506 argument, Sonnentag, Kuttler, and Fritz (2010) suggest that being occupied with non-work

507 activities that require the individual's full attention may facilitate psychological detachment.

508 Another aspect that has been demonstrated to improve psychological detachment is recovery-

509 related self-efficacy. Sonnentag and Kruel (2006) argue that like task-related self-efficacy

510 (Bandura, 1997) recovery-related self-efficiency can be improved through mastery

511 experience, vicarious learning and verbal persuasion. Based on the previously mentioned

512 arguments, Hahn, Binnewies, Sonnentag, \& Mojza (2011) developed a training program and

513 demonstrated beneficial impacts of this training on recovery experiences, recovery related

514 self-efficacy, and well-being.

515 Limitations and suggestions for further research

516 Despite the contributions, our studies are subject to several limitations, which need to

517 be discussed. First, most of the study variables were operationalized through self-report

518 measures. Thus, common method variance or a self-report bias might have contaminated the

519 relations observed (Podsakoff, MacKenzie, Lee, \& Podsakoff, 2003). However, our results 
520 show that psychological detachment interacts with SCDs but does not interact with job

521 ambiguity to predict emotional exhaustion and depersonalization. The differential influences

522 resulting from the combination of detachment with either SCDs or job ambiguity are unlikely

523 to be attributable to common method variance because such variance tends to blur differential

524 relationships. Furthermore, the differentiability of the predictors as well as the criterion

525 variables as indicated by CFAs also demonstrates that common method bias is rather

526 unlikely. Nevertheless, future research could gain more methodological clarity and practical

527 significance by considering more event-related and situation-based approaches for measuring

528 SCDs at work (Reis \& Gable, 2000).

529

The second limitation refers to the cross-sectional design of our studies. Although we

530 hypothesized a particular causal order of the variables, other causal directions or even

531 reciprocal relations could be possible as well. For example, an alternative reverse causal

532 interpretation of the results might be that employees in high strain jobs perceive self-control

533 demands as more threatening than employees in low strain jobs. However, several

534 longitudinal studies have provided strong empirical arguments against this hypothesis (for an

535 overview, see Zapf, Dormann, \& Frese, 1996). For example, drawing on a cross-lagged panel

536 design, Diestel and Schmidt (2011) have found SCDs to predict burnout and absenteeism

537 whereas, the lagged effects of burnout and absenteeism on SCDs at a later point in time failed 538 to reach significance.

539 The third limitation is related to our prediction that detachment is more effective in

540 buffering the adverse impact of SCDs than the adverse impact of job ambiguity on strain. Our

541 data showed that there was a significant difference between the interaction terms on the

542 outcomes of emotional exhaustion and depersonalization. However, our analyses failed to

543 provide corresponding differences between the interaction terms predicting ego depletion and

544 need for recovery. However, these results must be interpreted carefully because a 
545 precondition for the test to compare interaction terms is that these terms follow a normal

546 distribution. However, Kendall \& Stuart, (1958) demonstrated that interaction terms in

547 moderator analysis are not normally distributed. Hence, the test may have failed to

548 demonstrate significant differences in the outcomes ego depletion and need for recovery.

549 Furthermore, it is possible that methodological drawbacks such as measurement

550 deficits or flaws in study design (McClelland \& Judd, 1993) may have prevented us from

551 demonstrating moderating effects of detachment on the adverse impact of job ambiguity.

552 However, according to previous research the job ambiguity measure as it is used in our study

553 is valid and highly reliable (Breaugh \& Colihan, 1994; Schmidt \& Hollmann, 1998).

554 Accordingly, our measurement of job ambiguity is more reliable than our measurement of

555 SCDs (cf. Table 2). Thus, it is highly unlikely that measurement deficits have influenced our

556 results. Furthermore, because deficits in our study design (e.g. common method bias) should

557 apply to SCDs and job ambiguity likewise, it is also highly unlikely that these deficits have

558 influenced our results.

$559 \quad$ Additionally, one might argue that our findings concerning the absent moderating

560 effect of detachment on the adverse impact of job ambiguity may be random or exploratory in

561 nature. However, matching hypothesis suggests that a functional match between stressors and

562 buffering moderators increases the strength of interaction effects on strain (Cohen \& McKay,

563 1984; Cohen \& Wills, 1985). On the basis of the argument that SCDs deplete common

564 regulatory resources and detachment recovers these resources, psychological detachment

565 matches better with SCDs than with job ambiguity that relies for the most part on appraisal

566 mechanisms to cause strain. Thus, the effect of the SCDs-detachment interaction on strain

567 should be as hypothesized stronger than the effect of the job ambiguity-detachment

568 interaction on strain. Consequently, the demonstrated differential effects of detachment

569 correspond with the matching hypothesis and thus are not likely to reflect random effects. 
This theoretical notion is further supported by the fact that we demonstrated consistent

571 relationships of the SCDs-detachment interaction to four different indicators of strain that

572 according to our CFAs are distinct. In contrast, we consistently demonstrated that detachment

573 did not moderate the adverse impact of job ambiguity on all four indicators of strain. The

574 consistency of the differential effects on distinct indicators of strain strongly suggests that our

575 findings are not random or exploratory in nature but that we deliberately chose job ambiguity

576 as a stressor to demonstrate that detachment does not moderate all kinds of stressors.

\section{Conclusions}

578 In the present study, we analysed the impact of SCDs as a work stressor and

579 psychological detachment as a recovery experience on strain. In two different samples, we

580 were able to provide evidence that detachment attenuates the adverse effects of SCDs on

581 strain. Additionally, in the second sample we demonstrated that detachment was more

582 effective in buffering the adverse impact of SCDs than buffering the adverse impact of job

583 ambiguity. We hope that our study adds to the understanding of the relationships between

584 stressors, strain and buffering moderators and consequently provides employees and

585 organizations alike with the knowledge to protect employees from work-related stressors

586 depleting regulatory resources. 
589

590

591

592

593

594

595

596

597

598

599

600

601

602

603

604

605

606

607

608

609

610

611

Aiken, L. S., West, S. G. (1991). Multiple regression: Testing and interpreting interactions. Newbury Park: Sage.

Ashforth, B. E., Kreiner, G. E., \& Fugate, M. (2000). All in a day's work: Boundaries and micro role transitions. Academy of Management Review, 25(3), 472-491.

Bandura, A. (1997). Self-efficacy: The exercise of control. New York: W.H. Freeman.

Baumeister, R. F., Bratslavsky, E., Muraven, M., \& Tice, D. M. (1998). Ego depletion: Is the active self a limited resource? Journal of Personality and Social Psychology, 74(5), $1252-1265$.

Baumeister, R. F., Heatherton, T. F., \& Tice, D. M. (1994). Losing control: How and why people fail at self-regulation. San Diego: Academic Press.

Bertrams, A., Unger, A., \& Dickhäuser, O. (2011). Momentan verfügbare Selbstkontrollkraft - Vorstellung eines Messinstruments und erste Befunde aus pädagogischpsychologischen Kontexten. Zeitschrift für Pädagogische Psychologie, 25(3), 185 196.

Binnewies, C., Sonnentag, S., \& Mojza, E. J. (2009). Daily performance at work: Feeling recovered in the morning as a predictor of day-level job performance. Journal of Organizational Behavior, 30(1), 67-93.

Breaugh, J. A., \& Colihan, J. P. (1994). Measuring facets of job ambiguity: Construct validity evidence. Journal of Applied Psychology, 79(2), 191-202.

Büssing, A., \& Perrar, K.-M. (1992). Die Messung von Burnout. Untersuchung einer deutschen Fassung des Maslach Burnout Inventory (MBI-D). [Measuring burnout: A study of a German version of the Maslach Burnout Inventory (MBI-D).]. Diagnostica, $38(4), 328-353$. 
612 Cascio, W. F. (2003). Changes in Workers, work, and organizations. In W. C. Borman, D. R.

613

614

615

616

617

618

619

620

621

622

623

624

625

626

627

628

629

630

631

632

633

634

635

636 Ilgen, \& R. J. Klimoski (Eds.), Handbook of psychology (pp. 401-422). Hoboken, NJ: Wiley.

Ciarocco, N. J., Twenge, J. M., Muraven, M. \& Tice, D. M. (2007). Measuring state selfcontrol: Reliability, validity, and correlations with physical and psychological stress. Unpublished Manuscript, Monmouth University, NJ, USA.

Cohen, S., \& McKay, G. (1984). Social support, stress and the buffering hypothesis: A theoretical analysis. Handbook of psychology and health, 4, 253-267.

Cohen, S., \& Wills, T. A. (1985). Stress, social support, and the buffering hypothesis. Psychological bulletin, 98(2), 310.

Cohen, S., \& Wills, T. A. (1985). Stress, social support, and the buffering hypothesis. Psychological bulletin, 98(2), 310.

De Jonge, J., \& Dormann, C. (2006). Stressors, resources, and strain at work: A longitudinal test of the triple-match principle. Journal of Applied Psychology, 91(6), 1359.

Diestel, S., \& Schmidt, K.-H. (2011). Costs of simultaneous coping with emotional dissonance and self-control demands at work: Results from two German samples. Journal of Applied Psychology, 96, 643-653. doi:10.1037/a0022134

Diestel, S., \& Schmidt, K-H. (2012). Lagged mediator effects of self-control demands on psychological strain and absenteeism. Journal of Occupational and Organizational Psychology, 85(4), 556-578.

Etzion, D., Eden, D., \& Lapidot, Y. (1998). Relief from job stressors and burnout: Reserve service as a respite. Journal of Applied Psychology, 83(4), 577-585.

Hagger, M. S., Wood, C., Stiff, C., \& Chatzisarantis, N. L. D. (2010). Ego depletion and the strength model of self-control: A meta-analysis. Psychological Bulletin, 136(4), 495525. 
637 Hahn, V. C., Binnewies, C., Sonnentag, S., \& Mojza, E. J. (2011). Learning how to recover

638

639

640

641

642

643

644

645

646

647

648

649

650

651

652

653

654

655

656

657

658

659

660

661 from job stress: Effects of a recovery training program on recovery, recovery-related self-efficacy, and well-being. Journal of Occupational Health Psychology, 16(2), 202.

Kendall, M. G., \& Stuart, A. (1958). The Advanced Theory of Statistics, Vol. 1, London: Charles Griffin and Co.

Lanaj, K., Johnson, R. E., \& Barnes, C. M. (2014). Beginning the workday yet already depleted? Consequences of late-night smartphone use and sleep. Organizational Behavior and Human Decision Processes, 124(1), 11-23.

Maslach, C., \& Jackson, S. E. (1981). Maslach Burnout Inventory. Palo Alto, Calif: Consulting Psychologists Press.

Maslach, C., \& Jackson, S. E. (1986). Maslach Burnout Inventory (2nd ed.). Palo Alto, Calif: Consulting Psychologists Press.

McClelland, G. H., \& Judd, C. M. (1993). Statistical difficulties of detecting interactions and moderator effects. Psychological Bulletin, 114(2), 376-390.

Meijman, T., \& Mulder, G. (1998). Psychological aspects of workload. In P. J. D. Drenth, H. Thierry, \& C. J. D. Wolff (Eds.), Handbook of work and organizational psychology. Vol. 3. Personnel psychology (2nd ed.). Hove: Psychology Press.

Monat, A., Averill, J. R.., \& Lazarus, R. S. (1972). Anticipatory stress and coping reactions under various conditions of uncertainty. Journal of Personality and Social Psychology, 24(2), 237-253.

Muraven, M., \& Baumeister, R. F. (2000). Self-regulation and depletion of limited resources: Does self-control resemble a muscle? Psychological Bulletin, 126(2), 247-259.

Muraven, M., Tice, D. M., \& Baumeister, R. F. (1998). Self-control as a limited resource: Regulatory depletion patterns. Journal of Personality and Social Psychology, 74(3), 774-789. 
662 Neubach, B., \& Schmidt, K.-H. (2006). Beanspruchungswirkungen von

663

664

665

666

667

668

669

670

671

672

673

674

675

676

677

678

679

680

681

682

683

684

685

Selbstkontrollanforderungen und Kontrollmöglichkeiten bei der Arbeit. Zeitschrift für Psychologie, 214(3), 150-160.

Oaten, M., \& Cheng, K. (2005). Academic examination stress impairs self-control. Journal of Social and Clinical Psychology, 24(2), 254-279.

Podsakoff, P. M., MacKenzie, S. B., Lee, J.-Y., \& Podsakoff, N. P. (2003). Common method biases in behavioral research: A critical review of the literature and recommended remedies. Journal of Applied Psychology, 88(5), 879-903.

Pulakos, E. D., Arad, S., Donovan, M. A., \& Plamondon, K. E. (2000). Adaptability in the workplace: Development of a taxonomy of adaptive performance. Journal of Applied Psychology, 85(4), 612-624.

Reis, H. T., \& Gable, S. L. (2000). Event-sampling and other methods for studying everyday experience. In H. T. Reis \& C. M. Judd (Eds.), Handbook of research methods in social and personality psychology. New York: Cambridge University Press.

Rizzo, J. R., House, R. J., \& Lirtzman, S. I. (1970). Role conflict and ambiguity in complex organizations. Administrative science quarterly, 150-163.

Schmeichel, B. J., Vohs, K. D., \& Baumeister, R. F. (2003). Intellectual performance and ego depletion: Role of the self in logical reasoning and other information processing. Journal of Personality and Social Psychology, 85(1), 33-46.

Schmidt, K.-H. \& Diestel, S. (2012). The relation of self-control demands to job strain: The moderating role of organizational commitment. Applied Psychology: An International Review, 61(3), 479-497.

Schmidt, K. H., \& Hollmann, S. (1998). Eine deutschsprachige Skala zur Messung verschiedener Ambiguitätsfacetten bei der Arbeit. Diagnostica, 44(1), 21-29. 
686 Schmidt, K.-H., Hupke, M., \& Diestel, S. (2012). Does dispositional capacity for self-control

687

688

689

690

691

692

693

694

695

696

697

698

699

700

701

702

703

704

705

706

707

708 attenuate the relation between self-control demands at work and indicators of job strain? Work \& Stress, 26(1), 21-38.

Schmidt, K.-H., \& Neubach, B. (2007). Self-control demands: A source of stress at work. International Journal of Stress Management, 14(4), 398-416.

Sodenkamp, D., \& Schmidt, K.-H. (2000). Weiterentwicklung und Konstrukt-Validierung eines Verfahrens zur Messung erlebter Rollenambiguität bei der Arbeit. Zeitschrift für Arbeitswissenschaft, 54, 37-43.

Sonnentag, S., \& Bayer, U. V. (2005). Switching off mentally: Predictors and consequences of psychological detachment from work during off-job time. Journal of Occupational Health Psychology, 10(4), 393-414.

Sonnentag, S., Binnewies, C., \& Mojza, E. J. (2010). Staying well and engaged when demands are high: The role of psychological detachment. Journal of Applied Psychology, 95(5), 965-976.

Sonnentag, S., \& Fritz, C. (2007). The recovery experience questionnaire: Development and validation of a measure for assessing recuperation and unwinding from work. Journal of Occupational Health Psychology, 12(3), 204-221.

Sonnentag, S., \& Kruel, U. (2006). Psychological detachment from work during off-job time: The role of job stressors, job involvement, and recovery-related self-efficacy. European Journal of Work and Organizational Psychology, 15(2), 197-217.

Sonnentag, S., Kuttler, I., \& Fritz, C. (2010). Job stressors, emotional exhaustion, and need for recovery: A multi-source study on the benefits of psychological detachment. Journal of Vocational Behavior, 76(3), 355-365. 
709 Sonnentag, S., Unger, D., \& Nägel, I. J. (2013). Workplace conflict and employee well-

710 being: The moderating role of detachment from work during off-job time.

711 International Journal of Conflict Management, 24(2), 166-183.

712 Spiegel Online. (2011). Blackberry-brake: VW-Union enforces e-mail stop during leisure

713 time. (2011). Retrieved 11 February 2013 from

714 http://www.spiegel.de/wirtschaft/service/blackberry-pause-vw-betriebsrat-setzt-e-

715 mail-stopp-nach-feierabend-durch-a-805524.html.

716 Van Veldhoven, M. J. P. M., \& Broersen, S. (2003). Measurement quality and validity of the

717 "need for recovery scale". Occupational and Environmental Medicine, 60(suppl 1),

$718 \quad \mathrm{i} 3-\mathrm{i} 9$.

719 Zapf, D., Dormann, C., \& Frese, M. (1996). Longitudinal studies in organizational stress research: A review of the literature with reference to methodological issues. Journal of Occupational Health Psychology, 1(2), 145-169.

722

Zou, G. Y. (2007). Toward using confidence intervals to compare correlations. Psychological 723 Methods, 12(4), 399-413. 
Table 1

Means, Standard Deviations, Internal Consistencies (Cronbach's Alpha) and Intercorrelations (Study 1)

\begin{tabular}{|c|c|c|c|c|c|c|c|c|}
\hline Variable & 1 & 2 & 3 & 4 & 5 & 6 & 7 & 8 \\
\hline 1. Age & - & & & & & & & \\
\hline 2. Gender ${ }^{\mathrm{a}}$ & .13 & - & & & & & & \\
\hline 3. Self-control demands & .06 & .03 & $(.85)$ & & & & & \\
\hline 4. Psychological detachment & -.08 & -.03 & -.37 & $(.92)$ & & & & \\
\hline 5. Ego depletion & .09 & .03 & .46 & -.46 & $(.84)$ & & & \\
\hline 6. Need for recovery & .12 & -.07 & .44 & -.59 & .65 & $(.86)$ & & \\
\hline 7. Emotional exhaustion & .10 & .05 & .54 & -.55 & .73 & .78 & $(.90)$ & \\
\hline 8. Depersonalization & .04 & .11 & .37 & -.34 & .49 & .44 & .63 & $(.71)$ \\
\hline$M$ & 49.77 & 1.59 & 3.25 & 3.35 & 1.63 & 1.95 & 2.37 & 1.69 \\
\hline$S D$ & 6.00 & 0.49 & 0.67 & 0.85 & 0.55 & 0.65 & 1.00 & 0.76 \\
\hline
\end{tabular}

Note. ${ }^{\mathrm{a}}$ Gender $(1$ = female, 2 = male). Internal consistency estimates (Cronbach's alpha) are presented in parentheses in the diagonal.

Numbers in bold $p<.05 . N=445$. 
Table 2

Results of Confirmatory Factor Analyses for Testing the Differentiability of the Variables (Study 1)

\begin{tabular}{|c|c|c|c|c|c|c|c|c|}
\hline & $\chi^{2}$ & $d f$ & RMSEA & $C I_{90 \%(R M S E A)}$ & SRMR & CFI & $\mathrm{AIC}$ & $\mathrm{BIC}$ \\
\hline \multicolumn{9}{|c|}{ Measurement models of predictors } \\
\hline 2-factor model & $2.20^{n . s .}$ & 4 & .000 & $.000-.054$ & .006 & 1.000 & 3939.34 & 4004.91 \\
\hline 1-factor model ${ }^{\mathrm{a}}$ & $408.61^{* *}$ & 5 & .426 & $.391-.461$ & .147 & .621 & 4374.82 & 4436.29 \\
\hline \multicolumn{9}{|c|}{ Measurement models of criteria } \\
\hline 4-factor model & $19.51^{n . s .}$ & 14 & .030 & $.000-.058$ & .011 & .997 & 5848.68 & 5971.62 \\
\hline 1 -factor model ${ }^{\mathrm{b}}$ & $262.57^{* *}$ & 20 & .165 & $.148-.183$ & .062 & .872 & 6136.33 & 6234.68 \\
\hline
\end{tabular}

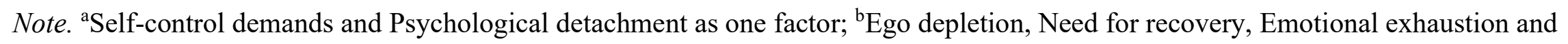
Depersonalization as one factor.

$* p<.05 . * * p<.01 . N=445$. 
Table 3

Regression Results ( $\beta$ Values) for Study 1.

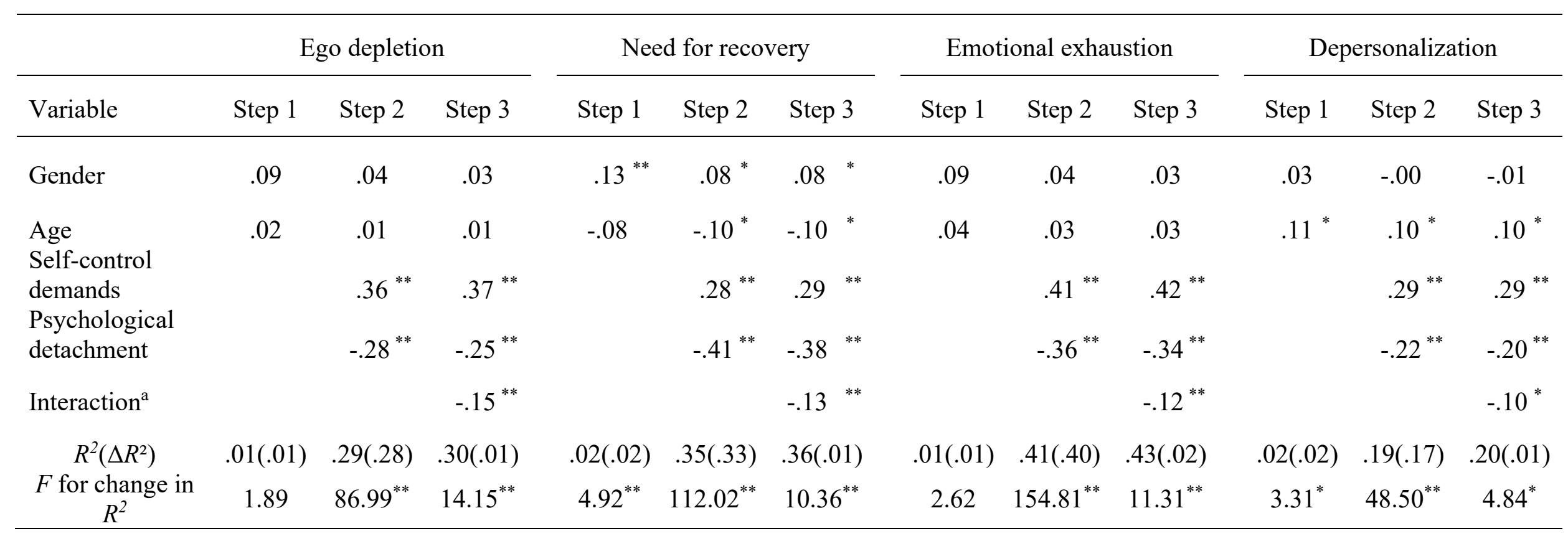

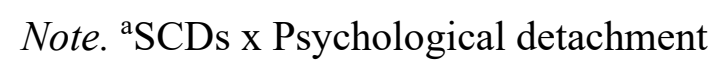

$* p<.05 . * * p<.01 . N=445$. 
Table 4

Means, Standard Deviations, Internal Consistencies (Cronbach's Alpha) and Intercorrelations (Study 2)

\begin{tabular}{|c|c|c|c|c|c|c|c|c|c|c|c|}
\hline Variable & 1 & 2 & 3 & 4 & 5 & 6 & 7 & 8 & 9 & 10 & 11 \\
\hline 1. Age & - & & & & & & & & & & \\
\hline 2. Gender $^{\mathrm{a}}$ & .12 & - & & & & & & & & & \\
\hline 3. Leadership position ${ }^{\mathrm{b}}$ & -.20 & -.27 & - & & & & & & & & \\
\hline 4. Working time status ${ }^{\mathrm{c}}$ & -.14 & -.43 & -.20 & - & & & & & & & \\
\hline 5. Self-control demands & .09 & -.01 & .03 & .03 & $(.80)$ & & & & & & \\
\hline 6. Job ambiguity & .16 & -.01 & .01 & -.06 & .21 & (90). & & & & & \\
\hline 7. Psychological detachment & -.05 & .00 & .07 & -.05 & -.42 & -.18 & (.93) & & & & \\
\hline 8. Ego depletion & .11 & -.02 & .16 & .05 & .45 & .33 & -.47 & $(.86)$ & & . & \\
\hline 9. Need for recovery & .08 & -.01 & .01 & .15 & .46 & .23 & -.59 & .64 & $(.86)$ & & \\
\hline 10. Emotional exhaustion & .03 & .04 & .10 & .11 & .53 & .37 & -.51 & .73 & .69 & $(.88)$ & \\
\hline 11. Depersonalization & -.14 & .14 & .01 & .12 & .34 & .37 & -.31 & .46 & .48 & .63 & $(.71)$ \\
\hline$M$ & 39.12 & 1.44 & 1.88 & 1.78 & 3.45 & 2.77 & 2.89 & 1.74 & 2.12 & 2.63 & 2.05 \\
\hline$S D$ & 10.64 & 0.50 & 0.33 & 0.42 & 0.56 & 0.95 & 0.97 & 0.56 & 0.68 & 0.93 & 0.87 \\
\hline
\end{tabular}

Note. ${ }^{\mathrm{a}}$ Gender $\left(1\right.$ = female, 2 = male), ${ }^{\mathrm{b}}$ Leadership position ( $1=$ leadership position, $2=$ no leadership position), ${ }^{\mathrm{c}}$ Working time status

$(1=$ part time, 2 = full time). Internal consistency estimates (Cronbach's alpha) are presented in parentheses in the diagonal.

Numbers in bold $p<.05 . N=426$. 
Table 5

Results of Confirmatory Factor Analyses for Testing the Differentiability of the Variables (Study 2)

\begin{tabular}{|c|c|c|c|c|c|c|c|c|}
\hline & $\chi^{2}$ & $d f$ & RMSEA & $C I_{90 \%(R M S E A)}$ & SRMR & CFI & AIC & $\mathrm{BIC}$ \\
\hline \multicolumn{9}{|c|}{ Measurement models of predictors } \\
\hline 3-factor model & $11.84 .^{n . s .}$ & 17 & .000 & $.000-.028$ & .012 & 1.000 & 6178.12 & 6287.59 \\
\hline 1-factor model ${ }^{\mathrm{a}}$ & $1401.44^{* *}$ & 20 & .403 & $.385-.421$ & .211 & .284 & 7580.47 & 7677.77 \\
\hline \multicolumn{9}{|c|}{ Measurement models of criteria } \\
\hline 4-factor model & $23.14^{\text {n.s. }}$ & 14 & .039 & $.000-.067$ & .014 & 0.996 & 5807.55 & 5929.18 \\
\hline 1 -factor model ${ }^{b}$ & $349.240^{* *}$ & 20 & .197 & $.179-.215$ & .066 & .848 & 6141.87 & 6239.18 \\
\hline
\end{tabular}


Table 6

Regression Results ( $\beta$ Values) for Study 2.

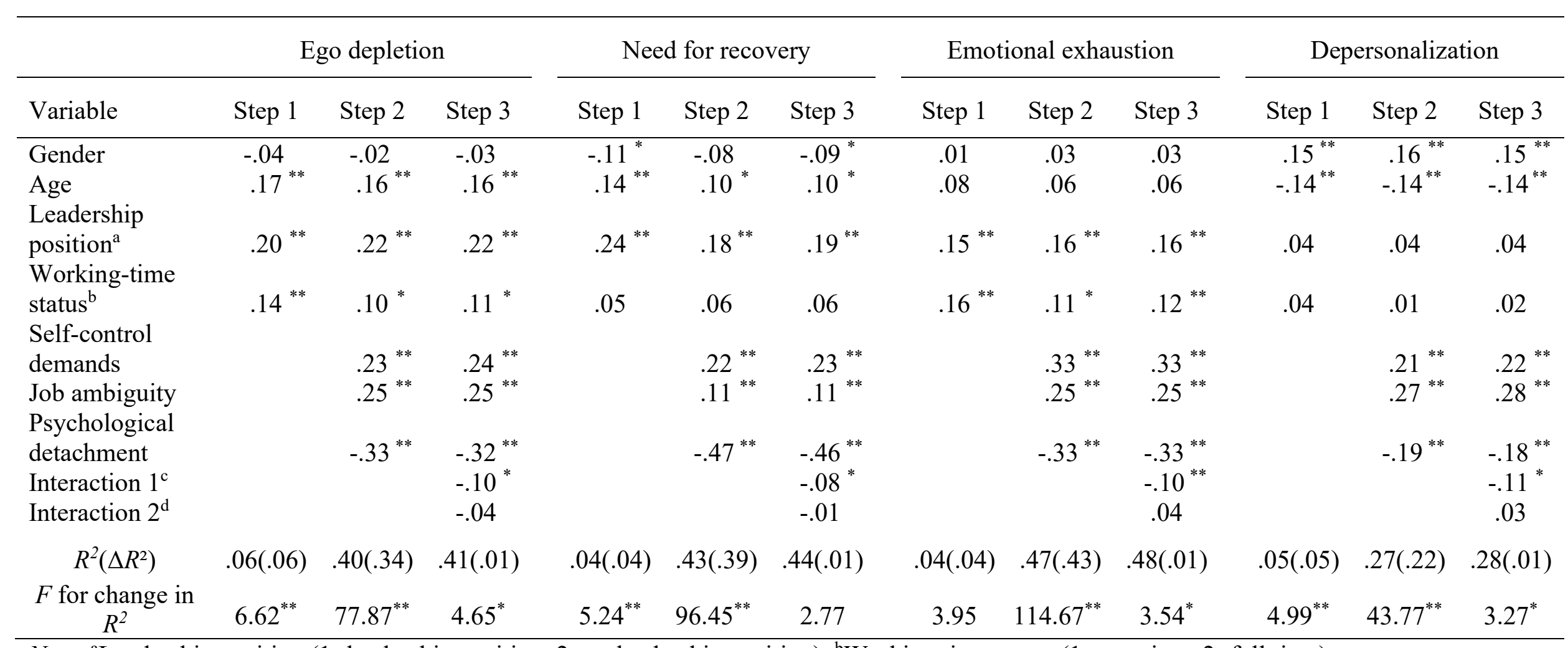

Note.${ }^{\mathrm{a}}$ Leadership position ( $1=$ leadership position, $2=$ no leadership position), ${ }^{\mathrm{b}}$ Working time status ( $1=$ part time, $2=$ full time)

${ }^{\mathrm{c} S C D s} \mathrm{x}$ Psychological detachment, ${ }^{\mathrm{d}} \mathrm{Job}$ ambiguity x Psychological detachment.

$* p<.05 . * * p<.01 . N=426$ 
Figure captions

Figure 1. Interaction effects of SCDs and Psychological detachment on Ego depletion, Need for recovery, Emotional exhaustion and Depersonalization (Study 1).

Figure 2. Interaction effects of SCDs and Psychological detachment on Ego depletion, Need for recovery, Emotional exhaustion and Depersonalization (Study 2). 
Figure 1.
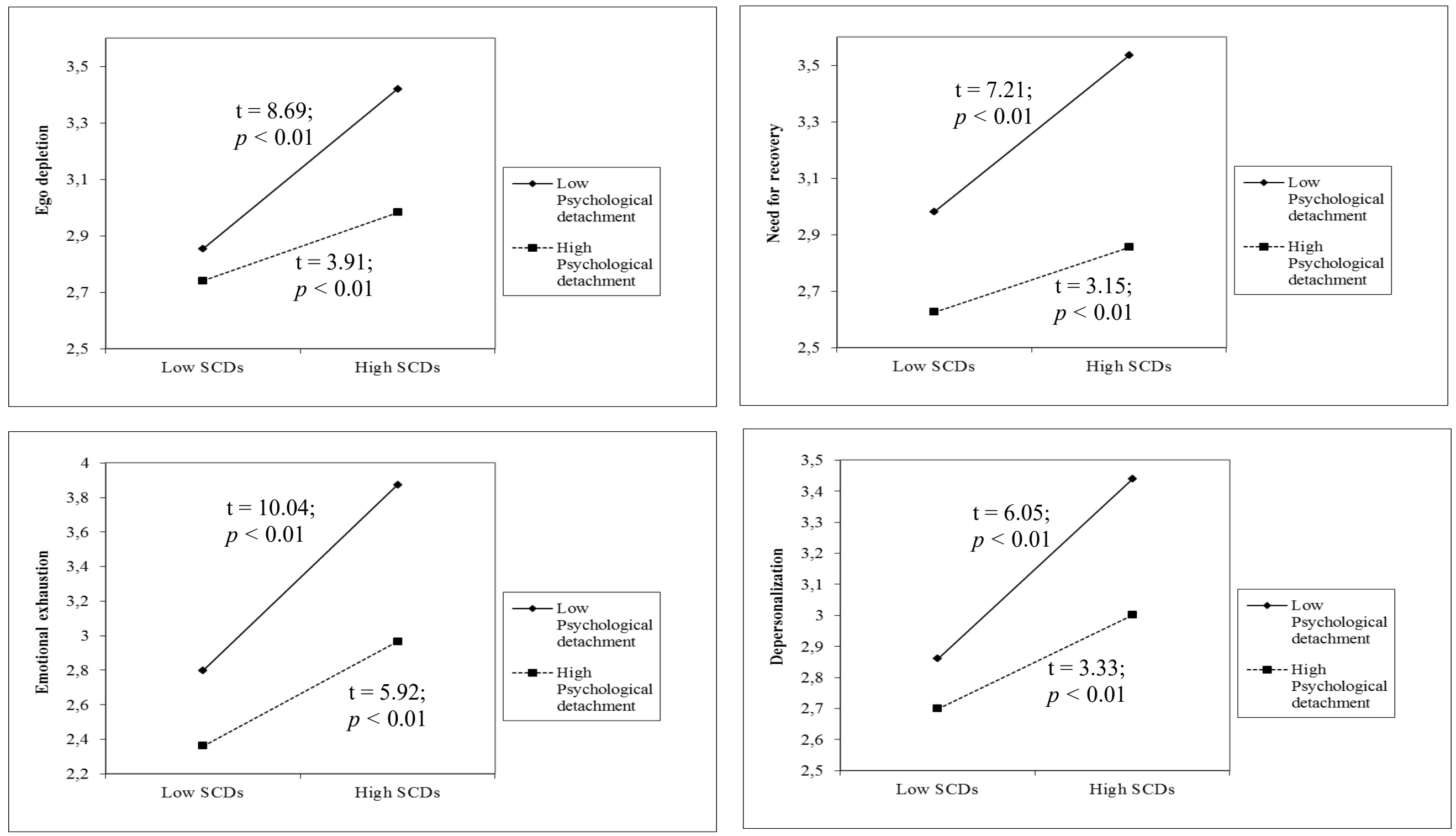
Figure 2.
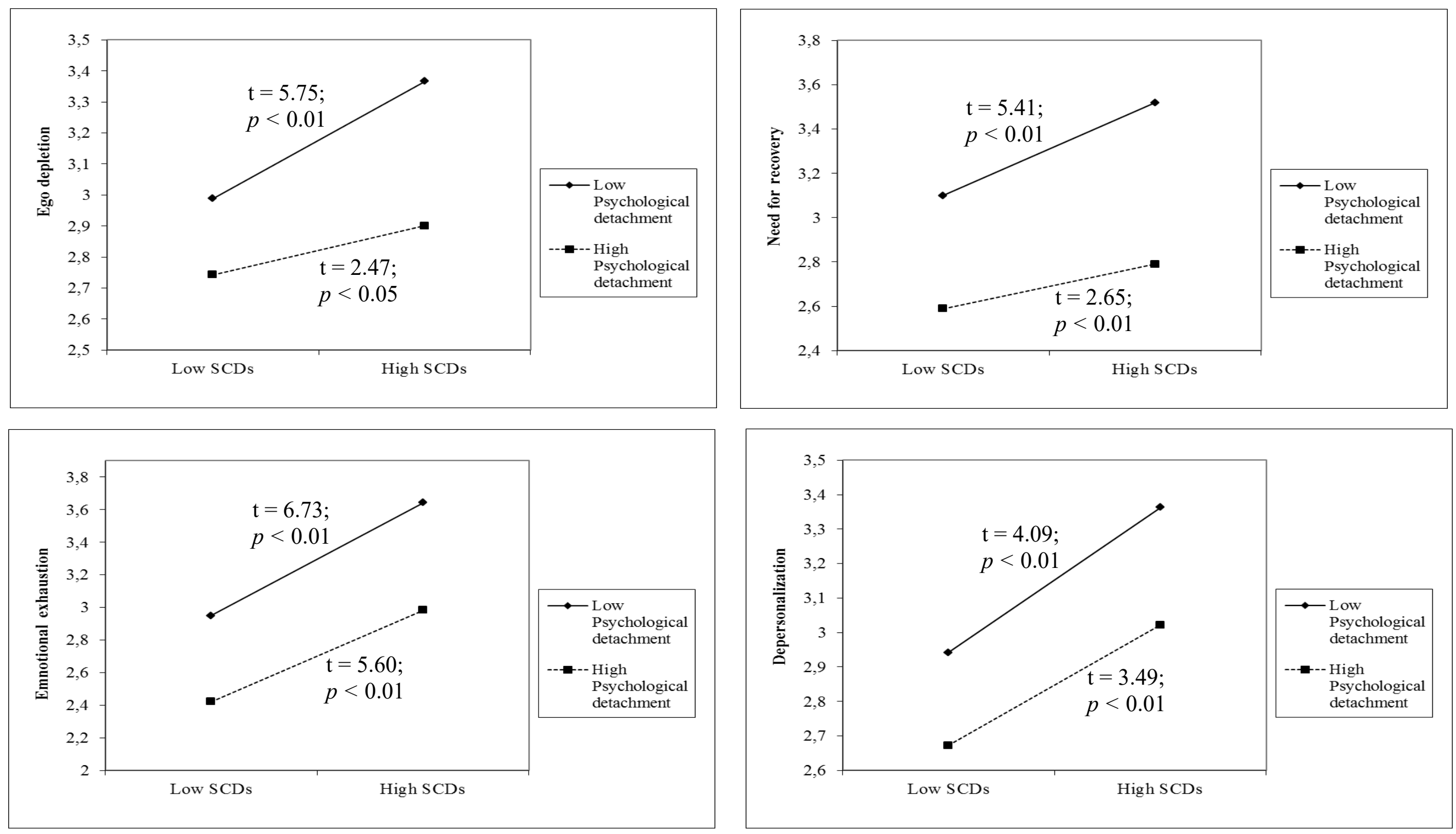